\title{
Pancreatic duct stricture dilation with \\ a controlled radial expansion balloon for the management of stone impaction
}
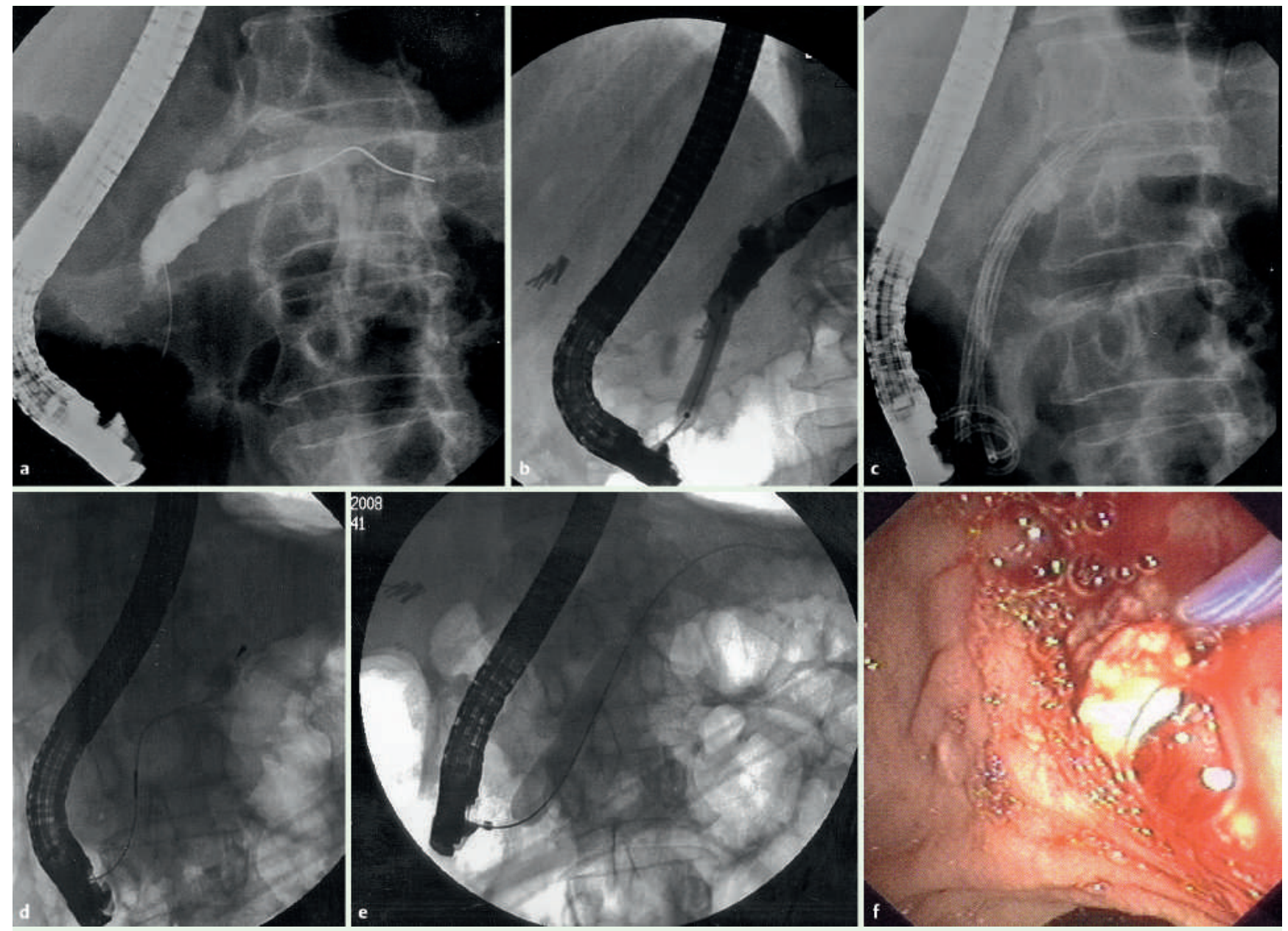

Fig. 1 a Pancreatic duct stricture. b Dilating the stricture with a biliary balloon. $\mathbf{c}$ Plastic stents and the pancreatic stone. $\mathbf{d}$ Stone captured with the basket and pushed back to the dilated portion of the duct. $\mathbf{e}$ Dilating the stricture with a controlled radial expansion balloon. $\mathbf{f}$ Endoscopic image of stone extraction.

A 54-year-old woman was treated following episodes of epigastric pain due to a large stone in the main pancreatic duct and a long (approximately $3 \mathrm{~cm}$ ) stricture at the head of the pancreas $(\bullet$ Fig. 1 a). She underwent endoscopic retrograde cholangiopancreatography (ERCP), where dilation of the pancreatic duct was performed using an 8-mm biliary dilating balloon (Boston Scientific, Natick, Massachusetts, USA) ( $\bullet$ Fig. 1b). Four single pig-tail pancreatic stents $(7 \mathrm{Fr} \times 8 \mathrm{~cm})$ were placed ( $\bullet$ Fig. 1 c). During a second ERCP 3 months later, the stents were retrieved and the pancreatic stricture was further dilated with a $10-\mathrm{mm}$ biliary dilating balloon (Cook Medical, Blooming- ton, Indiana, USA). A new attempt to remove the stone using an extraction balloon (Cook Medical) was unsuccessful. We then used a dormia basket; however, this became impacted with the stone inside it. A 10-11-12 controlled radial expansion (CRE) balloon (Boston Scientific) was then advanced parallel to the basket wire, in order to push the stone to the dilated portion of the duct ( $\bullet$ Fig. 1 d), and then further dilation of the stricture with the same balloon was performed. To our surprise, a new attempt to retrieve the stone was again unsuccessful. We then tried to dilate the pancreatic duct even further, with a 12-13.5-15 CRE balloon ( Fig. 1e). Following this procedure, the basket and the stone were finally removed ( $\bullet$ Fig. 1 f). To finish, a single pigtail pancreatic stent, $7 \mathrm{Fr} \times 8 \mathrm{~cm}$, was placed to prevent pancreatitis. The patient progressed well and was discharged 2 days later.

According to our knowledge, this is the first reported use of a balloon dilator larger than $10 \mathrm{~mm}$ in the pancreatic duct [1 - 3]. To date, CRE balloons, the only alternative to existing biliary balloon dilators, which do not exceed this diameter, have only been used to dilate the biliary sphincterotomy site and retrieve large bile duct stones $[4,5]$.

Endoscopy_UCTN_Code_TTT_1AR_2AI 
N. Viazis' ${ }^{1}$, G. Stefanidis ${ }^{2}$, A. Katsikani², D. Pleskow ${ }^{3}$, R. Chuttani ${ }^{3}$

1 2nd Department of Gastroenterology, Evangelismos Hospital, Athens, Greece

2 Athens Naval Hospital, Athens, Greece

3 Beth Israel Deaconess Medical Center, Boston, Massachusetts, USA

\section{References}

1 Mayedo A, Soehendra N, Reddy N, Bhandari S. Endotherapy for chronic pancreatitis with intracanalar stones. Endoscopy 2007; 39: 653-658

2 Binmoeller K, Rathod V, Soehendra N. Endoscopic therapy of pancreatic strictures. Gastrointest Endosc Clin N Am 1998; 8: 125 142

3 Costamagna G, Bujalic M, Tringali A et al. Results of multiple pancreatic stenting in chronic pancreatitis. Endoscopy 2006; 38 : 254-259

4 Heo J, Kang $D$, Jung $H$ et al. Endoscopic sphincterotomy plus large balloon dilation versus endoscopic sphincterotomy for removal of bile duct stones. Gastointestina Endosc 2007; 66: 720-726

5 Misra S, Dwivedi M. Large diameter balloon dilation after ES for difficult bile duct stones. Endoscopy 2008; 40: 209-13
Bibliography

DOI $10.1055 / \mathrm{s}-0028-1119605$

Endoscopy 2009; 41: E106-E107

(c) Georg Thieme Verlag KG Stuttgart · New York . ISSN 0013-726X

\section{Corresponding author}

\section{N. Viazis, MD}

2nd Department of Gastroenterology,

Evangelismos Hospital

59 Niriidon Street

17561 P. Faliro

Athens

Greece

Fax: +30-210-7233671

Nikos.Viazis@gmail.com 